\title{
Perceptions of Factors Affecting Milk Quality and Safety among Large- and Small-Scale Dairy Farmers in Zimbabwe
}

\author{
Annah Shingirai Paraffin (D), Titus Jairus Zindove $(\mathbb{D})$, and Michael Chimonyo $(\mathbb{D}$ \\ Animal and Poultry Science, School of Agriculture, Earth and Environmental Sciences, University of KwaZulu-Natal, \\ P. Bag X01, Scottsville, Pietermaritzburg 3209, South Africa
}

Correspondence should be addressed to Michael Chimonyo; michaelchimonyo@gmail.com

Received 25 July 2017; Revised 17 November 2017; Accepted 5 December 2017; Published 15 January 2018

Academic Editor: Maria Rosaria Corbo

Copyright (c) 2018 Annah Shingirai Paraffin et al. This is an open access article distributed under the Creative Commons Attribution License, which permits unrestricted use, distribution, and reproduction in any medium, provided the original work is properly cited.

The study investigated the perceptions of milk producers on milk quality and safety. Randomly selected large-scale farmers $(n=158)$ and small-scale farmers $(n=186)$ were surveyed using semistructured questionnaires. An ordinal logistic regression was used to estimate the probability of farmers considering milk quality and safety important. Large-scale farmers were 3 times more likely to consider that breed affects milk quality compared to their small-scale counterparts. Farmers aged over 30 years were 3 times more likely to indicate that hygiene affected milk quality. The likelihood of milk transportation affecting its quality was 4 times higher in small-scale farmers compared to large-scale producers. Postmilking contamination of milk was perceived to occur during transportation by small-scale farmers, whilst commercial farmers ranked storage as the important source of contamination after milking. Udder diseases were ranked first by large-scale farmers while small-scale farmers ranked milking environment as the major cause of milk spoilage. The likelihood of milk safety being important was two times higher in large farms compared to small-scale farms. Intervention programmes on milk safety should mainly target small-scale dairy farmers since they are less concerned about milk quality and safety.

\section{Introduction}

Dairy production plays a vital role in numerous national economies through provision of employment, food security, and sustainable income [1]. For example, in Sub-Saharan Africa, the dairy industry is a major contributor to gross domestic product. Milk and dairy products play a crucial role through provision of healthy food and balanced diets. In SubSaharan Africa, dairy products are easy to access as a source of nutrients compared to meat. The industry, in general, is made of different sized farms and processors ranging from smallto large-scale operations. Smallholder dairy farming refers to the economic activity of keeping dairy cows with an average herd size of less than seven (7) milking cows on less than one hectare of land [2].

Both large- and small-scale dairy farmers operate under highly uncertain production and economic environments. One of the biggest concerns of dairy farmers is the quality and safety of milk production. Failure to meet quality assurance standards and regulatory requirement affects both the farmers and consumers. Penalties imposed for production of poor quality milk reduce income for farmers. Consumers are exposed to potential public health threats and diseases from consumption of potentially contaminated milk sources. At the same time, farmers also face other challenges such as increased production costs, low productivity, low milk prices, lack of liquidity or capitalization, and poor input support [3]. For example, in Zimbabwe, the drop in milk production over the last decade has been attributed to liquidity crunch, small herds, and lack of cheap lines of credit [4]. The dairy industry has not been spared from the adverse effects of drought and extreme temperatures. Despite these challenges the farmers are still expected by all stakeholders to produce good quality milk that is free from microbial, physical, and chemical contamination [5].

Milk and its products are rich in nutrients and contain high moisture and neutral $\mathrm{pH}$. Milk, thus, easily favours the growth and multiplication of bacteria and other diseasecausing agents. Contaminated milk may cause tuberculosis, brucellosis, listeriosis, gastrointestinal disorders, and 
salmonellosis. Milk contamination can originate from different sources such as the milking environment, wind, milking equipment, feeds, soil, faeces, farm personnel, and housing [6]. Although contamination of milk can occur at various stages including during handling, during transportation or storage at farm, and during processing or at the market, most of the contamination is usually associated with the farm. Therefore, it is important to put in place sound quality control measures at the farm level.

Poor hygiene practices at the farm level have been reported to be the main cause for poor productivity and income losses for the smallholder sector [4]. Research shows that high total bacteria count (TBC) is positively correlated with unsanitary conditions associated with dirty udders before milking, inadequate or poor teat sanitation, poor cleaning and sanitation of milking equipment, and inadequate cooling of milk [5, 7]. Other elements that influence TBC include health and hygiene of the cow, housing and management, cleaning and sanitizing procedures, farm milking environment, and quality of cleaning water [8].

In most countries, there are regulatory agencies that monitor the quality of milk delivered to and processed by various processors. Milk is routinely checked for TBC, somatic cell counts (SCC), fat content, protein, lactose, and solids nonfat (SNF). For example, in Zimbabwe farmers are paid a premium based on the quality of milk. Most of the small-scale dairy farmers do not have facilities for bulk milk collection due to low milk volumes produced. They deliver their milk to nearby Milk Collection Centres (MCCs) where their milk is pooled. Farmers in such cases have their premium based on the group milk quality. This means that farmers with good production systems may be disadvantaged by the poor performers. These resource poor small-scale farmers' milk quality issues are further compounded by transportation time and mode and distance to milk processors.

As the demand for safe milk and dairy products increases, the importance of an integrated approach for ensuring safety throughout the whole supply chain becomes important. To ensure production of quality milk, it is necessary to understand the various causes and sources of milk contamination at the farm level. The use of food safety and quality assurance systems at the farms is important to reduce contaminants in milk and dairy products. Policy makers and regulators should be in touch with the sources of contamination of milk products so as to implement long-term planning for clean and safe milk production.

Understanding farmer perceptions and attitudes towards clean and safe milk production contributes to clean milk production practised on farms. Factors affecting consumer perceptions on general food safety are fairly well-understood [9-11]. There is limited information on dairy farmers in Sub-Saharan Africa. Given that many dynamic and complex factors affect quality of milk, it is crucial to determine those elements which the farmers are likely to consider to be important. Understanding this will not only form the basis of intervention programmes for clean milk production but also assist farmers in putting in place mechanisms that ensure safe and profitable milk production. The current study was conducted to compare perceptions of large- and small-scale farmers on milk quality and safety. It was hypothesized that perceptions of milk quality and safety of large- and smallscale farmers differ.

\section{Materials and Methods}

2.1. Study Site. Data were collected from dairy farmers from Mashonaland and Manicaland provinces of Zimbabwe in December 2016. Data were collected from dairy farmers from Mashonaland and Manicaland provinces of Zimbabwe in December 2016. These two provinces are in agricultural regions 1 to 3 . Average rainfall in both provinces is between 600 and $1200 \mathrm{~mm}$ per annum. The provinces also have the largest concentration of small-scale and large-scale dairy farmers and Milk Collection Centres (MCC). Manicaland province is situated at $18.9216^{\circ} \mathrm{S}$ and $32.1746^{\circ} \mathrm{E}$. Mashonaland is subdivided into three regions, namely, Mashonaland Central East and West provinces that are situated at $16.7644^{\circ} \mathrm{S}$, $31.0794^{\circ} \mathrm{E}, 18.5872^{\circ} \mathrm{S}, 31.2626^{\circ} \mathrm{E}, 17.4851^{\circ} \mathrm{S}$, and $29.7889^{\circ} \mathrm{E}$, respectively. Large-scale farmers deliver the bulk of their milk to the dairy processors. The milk from small-scale farmers that is not sold directly to the public is supplied to MCCs and various processors that manufacture long life milk, pasteurised milk, cheese, cream, butter, fermented milk, buttermilk, and fruit blends. The other agricultural practices in these two provinces include intensive and extensive livestock production, periurban farming, horticulture, and field crop production. Small-scale dairy farming involves keeping a small herd of dairy animals usually less than seven milking cows on less than a hectare of land [2].

2.2. Sampling Procedure and Data Collection. Data were generated using a survey conducted by interviewing farmers selected from two production systems, large-scale and small-scale farmers. A database containing all registered large- and small-scale dairy farmers, their contact details, and addresses was obtained from Dairy Services Zimbabwe Limited. A total of 156 small-scale farmers and 186 largescale farmers were randomly selected from the database. Table 1 shows sociodemographic characteristics, mean herd size, and the number of respondents from each production system. The selected farmers were visited and interviewed by trained enumerators at their homesteads using a pretested questionnaire. The questionnaire had been pilot-tested on 14 randomly selected farmers. The survey captured aspects on sociodemographic and economic characteristics, milk production patterns, perceptions on milk safety, concerns on milk safety, and factors affecting milk quality. Sociodemographic characteristics captured included household size, age, gender, and educational level of farmer. A farmer was considered educated if he or she had received education above primary school level. Farmers who had primary school level education or less were considered uneducated. Each farmer was asked to rank the causes of milk spoilage during milking and sources of contamination of milk postmilking. The farmers were also asked whether they are concerned or not concerned about milk safety and whether they considered milk quality important or not important. The farmers were also asked whether they thought factors such as milking 
TABLE 1: Sociodemographic characteristics, mean herd size $( \pm S D)$, and the number of respondents from each production system.

\begin{tabular}{|c|c|c|}
\hline Class & Large-scale & Small-scale \\
\hline$n$ & 158 & 186 \\
\hline \multicolumn{3}{|l|}{ Age (\%) } \\
\hline Young (<30 years) & 35.5 & 13.5 \\
\hline Old (>30 years) & 64.5 & 86.5 \\
\hline \multicolumn{3}{|l|}{ Household size (\%) } \\
\hline Small (<4 people) & 40.8 & 37.3 \\
\hline Large ( $>4$ people) & 59.2 & 67.1 \\
\hline \multicolumn{3}{|l|}{ Marital status (\%) } \\
\hline Married & 8.2 & 50.0 \\
\hline Single & 21.8 & 42.9 \\
\hline Divorced & 44.5 & 6.4 \\
\hline Widowed & 25.5 & 0.8 \\
\hline \multicolumn{3}{|l|}{ Highest education level (\%) } \\
\hline No formal education & 16.9 & 19.8 \\
\hline Primary & 33.8 & 17.5 \\
\hline Secondary & 35.1 & 41.3 \\
\hline Tertiary & 14.3 & 21.4 \\
\hline \multicolumn{3}{|l|}{ Cow herd size } \\
\hline & $184 \pm 18.7^{\mathrm{a}}$ & $10 \pm 6.3^{\mathrm{b}}$ \\
\hline
\end{tabular}

method, breed of cows, hygiene, and mode of transport affected milk quality. The study was granted the ethical clearance certificate AREC/080/016D by the University of KwaZulu-Natal's Research Ethics Committee.

2.3. Statistical Analyses. Data were analysed using Statistical Analysis System 9.2 [12]. Descriptive statistics and frequency distributions for categorical variables were used to describe the data. Mean rank scores for the causes of milk contamination and spoilage were determined using PROC MEANS of SAS [12]. An ordinal logistic regression (PROC LOGISTIC) model was used to estimate the probability of farmers perceiving specific milk quality attributes being important. The logit model tested effects of production system (large- and small-scaled), household size, age, gender, and educational level of farmer.

The logit model used was

$$
\ln \left[\frac{P}{1-P}\right]=\beta_{0}+\beta_{1} X_{1}+\beta_{2} X_{2}+\cdots+\beta_{t} X_{t}+\varepsilon,
$$

where $P$ is probability of farmers (considering a particular factor affecting milk quality); $[P / 1-P]$ are odds of farmers' households (considering milk quality important; concerned about the milk safety); $\beta_{0}$ is intercept; $\beta_{1} X_{1} \cdots \beta_{t} X_{t}$ are regression coefficients of predictors; $\varepsilon$ is random residual error.

\section{Results}

3.1. Factors Affecting Milk Quality. The odds ratio estimates of factors affecting milk quality are shown in Table 2. Largescale farmers were 3 times more likely to consider breed to affect milk quality, when compared with small-scale farmers. Farmers aged over 30 years were 3 times more likely to indicate that hygiene affected milk quality. Small-scale farmers were 4 times more likely to consider transport a main contributor to poor milk quality when compared to the commercial farmers.

3.2. Causes of Milk Spoilage and Source of Contamination. Table 3 shows the farmers' rankings of reasons for causes of milk spoilage during milking for large-scale and smallscale dairy farms. Whilst the large-scale farmers ranked udder diseases highest as the major cause of milk spoilage, small-scale farmers ranked milking environment as the highest contributor to milk spoilage during milking. Udder diseases were ranked second by small-scale farmers. For both, production systems personnel were considered the least cause for milk spoilage. The mean rank scores of sources of contamination postmilking are shown in Table 4. Mean rank scores of transportation and processing as sources of postmilking contamination differed with production system $(P<0.01)$. While small-scale farmers ranked transportation as the most important source of postmilking contamination, large-scale farmers ranked it least. Storage was ranked as the most important source of postmilking contamination by large-scale farmers. The small-scale farmers considered milking machinery as the least contributor to postmilking contamination.

3.3. Milk Quality and Safety. The odds ratio estimates of farmers being concerned about milk quality are shown in Table 5. The small-scale farmers were 4.5 times more likely to be concerned about milk quality than the large-scale 
TABLE 2: Odds ratio estimate and lower (LCI) and upper confidence interval (UCI) of farmers indicating that different factors affect milk quality.

\begin{tabular}{|c|c|c|c|c|c|}
\hline Factor & Predictor & Odds & LCI & UCI & Sig. \\
\hline \multirow{5}{*}{ Milking method } & Production system (large- versus small-scale) & 0.70 & 0.38 & 1.27 & NS \\
\hline & Gender (female versus male) & 1.29 & 0.77 & 2.17 & NS \\
\hline & Age (young versus old) & 1.56 & 0.83 & 2.96 & NS \\
\hline & Household size (small versus large) & 1.00 & 0.98 & 1.02 & NS \\
\hline & Education (uneducated versus educated) & 0.87 & 0.53 & 1.43 & NS \\
\hline \multirow{5}{*}{ Breed } & Production system (large- versus small-scale) & 3.05 & 1.66 & 5.62 & * \\
\hline & Gender (male versus female) & 0.73 & 0.44 & 1.23 & NS \\
\hline & Age (young versus old) & 1.08 & 0.57 & 2.04 & NS \\
\hline & Household size (small versus large) & 0.99 & 0.97 & 1.07 & NS \\
\hline & Education (uneducated versus educated) & 1.43 & 0.87 & 2.36 & NS \\
\hline \multirow{5}{*}{ Hygiene } & Production system (large- versus small-scale) & 1.04 & 1.57 & 1.91 & * \\
\hline & Gender (male versus female) & 0.83 & 0.49 & 1.41 & NS \\
\hline & Age (young versus old) & 0.54 & 0.34 & 0.98 & * \\
\hline & Household size (small versus large) & 1.17 & 0.69 & 1.97 & NS \\
\hline & Education (uneducated versus educated) & 0.74 & 0.45 & 1.23 & NS \\
\hline \multirow{5}{*}{ Transport } & Production system (large- versus small-scale) & 0.46 & 0.25 & 0.84 & * \\
\hline & Gender (female versus male) & 1.29 & 0.76 & 2.18 & NS \\
\hline & Age (young versus old) & 0.83 & 0.43 & 1.58 & NS \\
\hline & Household size (small versus large) & 0.95 & 0.74 & 1.21 & NS \\
\hline & Education (uneducated versus educated) & 0.69 & 0.42 & 1.13 & NS \\
\hline
\end{tabular}

LCI: lowest confidence interval, UCI: upper confidence interval, Sig.: significance, NS: not significant $(P>0.05),{ }^{*} P<0.05$; higher odds ratio estimates indicate greater difference in preference levels of predictors.

TABLE 3: Mean rank score (ranks) for causes of milk spoilage during milking in commercial and small-scale dairy farms.

\begin{tabular}{lccc}
\hline Source & Large-scale & Small-scale & Significance \\
\hline Personnel & $3.21(4)$ & $3.08(4)$ & NS \\
Containers & $3.04(3)$ & $2.93(3)$ & NS \\
Milking environment & $2.14(2)$ & $1.97(1)$ & NS \\
Udder diseases & $1.70(1)$ & $2.17(2)$ & $* *$ \\
\hline
\end{tabular}

The lower the mean rank score (rank), the more important the cause of spoilage; ${ }^{* *} P<0.01$; NS: not significant $(P>0.05)$.

TABLE 4: Mean rank score (ranks) for sources of contamination postmilking in commercial and small-scale dairy farms.

\begin{tabular}{lccc}
\hline When contamination occurs & Large-scale & Small-scale & Significance \\
\hline Milking machinery & $2.72(3)$ & $2.79(4)$ & NS \\
Storage & $2.14(1)$ & $2.32(2)$ & NS \\
Transportation & $2.79(4)$ & $2.16(1)$ & $* *$ \\
Processing & $2.29(2)$ & $2.75(3)$ & $*$ \\
\hline
\end{tabular}

The lower the mean rank score (rank), the more important the source of contamination; ${ }^{*} P<0.05 ;{ }^{* *} P<0.01$; NS: not significant $(P>0.05)$.

TABLE 5: Odds ratios estimates and lower (LCI) and upper confidence interval (UCI) of farmers being concerned about milk quality.

\begin{tabular}{lcccc}
\hline Predictor & Odds & LCI & UCI & Significance \\
\hline Production system (large- versus small-scale) & 0.22 & 0.09 & 0.51 & $*$ \\
Gender (male versus female) & 0.83 & 0.43 & 1.63 & NS \\
Age (young versus old) & 0.99 & 0.41 & 2.43 & NS \\
Household size (small versus large) & 0.93 & 0.47 & 1.82 & NS \\
Education (uneducated versus educated) & 1.13 & 0.60 & 2.13 & NS \\
\hline
\end{tabular}

LCI: lowest confidence interval, UCI: upper confidence interval, Sig.: significance, NS: not significant $(P>0.05),{ }^{*} P<0.05$; higher odds ratio estimates indicate greater difference in preference levels of predictors. 
TABLE 6: Odds ratios estimates and lower (LCI) and upper confidence interval (UCI) of farmers considering milk safety to be important.

\begin{tabular}{lcccc}
\hline Predictor & Odds & LCI & UCI & Significance \\
\hline Production system (large- versus small-scale) & 2.19 & 1.17 & 4.08 & $*$ \\
Gender (male versus female) & 1.29 & 0.71 & 2.37 & NS \\
Age (young versus old) & 0.99 & 0.48 & 2.07 & NS \\
Household size (small versus large) & 1.12 & 0.61 & 2.05 & NS \\
Education (uneducated versus educated) & 13.61 & 6.79 & 28.80 & $*$ \\
\hline
\end{tabular}

LCI: lowest confidence interval, UCI: upper confidence interval, Sig.: significance, NS: not significant $(P>0.05),{ }^{*} P<0.05$; higher odds ratio estimates indicate greater difference in preference levels of predictors.

farmers. Table 6 shows the odds ratios of farmers considering the importance of milk safety. The likelihood of milk safety being important was two times higher for large-scale farmers compared to the small-scale farmers $(P<0.05)$. Educated dairy farmers were more likely to consider milk safety important than their uneducated counterparts $(P<0.05)$.

\section{Discussion}

The study was designed to explore the factors affecting milk quality and perceptions of farmers on causes of poor milk quality in large- and small-scale farms. Understanding the perceptions of farmers on milk quality and safety assists policy makers and stakeholders in the dairy industry to put in place interventions for clean, safe, and profitable milk production.

The majority of farmers in the study were adults above 30 years of age. It could be possible that fewer younger farmers are engaged in dairy farming, especially in Southern Africa. Dairy enterprises require huge capital investments for purchasing heifers, equipment, or feeds, which may not be easily available to younger farmers [5]. It is also likely that, owing to the prevailing economic hardships in most developing countries, there are few financial institutions that offer credit facilities that can be easily accessed by resource poor youth $[4,13]$. Therefore, challenges hindering the youths in participating in dairying farming need to be explored.

The finding that the large-scale farmers were more likely to consider breed of cows an important factor affecting milk quality when compared to the small-scale farmers agrees with Huijps et al. [14] who reported that breed type can affect milk quality. A lot of work has gone into the selection of dairy breeds based on milk production potential and disease resistance [15]. The majority of large-scale farmers consider the breeds to use on their farms based on the resistance to diseases such as mastitis, plus other milk production characteristics. Mastitis is the most common and costly disease which can contribute to economic losses due to penalties for dairy farmers $[14,15]$. The large-scale farmers preferred Jersey and Holstein, while the small-scale farmers had mixed breeds. The finding that large-scale and older farmers who had more years of experience in dairy farming considered hygiene an important factor affecting milk quality agreed with findings by several authors $[5,7,16]$. These authors reported that the production of high quality milk is positively correlated with maintenance of hygienic standards in the milking facilities and cow cleanliness during milking.
Following strict hygienic standards prevents intramammary infections during milking and ensures lower total bacteria counts in milk [17]. The finding that the older farmers, aged over 30 years, were more likely to indicate that hygiene affected milk quality could also have been influenced by those farmers' exposure, knowledge, and experience in dairying. It is possible that over the years of being involved in dairy farming, older farmers could have seen the impact that poor hygiene has on productivity and profitability. Therefore, they could be more likely to consider hygiene as an important factor compared to the younger farmers with less dairy farming experience.

The finding that small-scale farmers considered transportation as the main contributor to poor milk quality when compared to the commercial farms could have been influenced by the fact that small-scale farmers lack access to good transportation modes and road network facilities. Most of the small-scale farmers transport their milk on foot, scotch-carts, bicycles, and public transport. [1, 4]. It is possible that milk quality will deteriorate because of the distances and time it takes to reach the processor, due to lack of adequate cooling facilities. Yet for most large-scale farmers, milk is transported in bulk in refrigerated trucks with good temperature control mechanisms. The finding that transportation was ranked highest as the major source of milk contamination by the small-scale farmers was, therefore, expected. Most small-scale farmers in this study transported their milk via public transport, commuter omnibuses, owned vehicles, and animal drawn scotch-carts.

The finding that large-scale farmers ranked udder diseases as the main cause of milk spoilage is supported by another researcher's finding which confirms that the presence of udder diseases such as mastitis in cows is the main contributor to poor milk quality as evidenced by the high level of somatic cell counts [16]. For this reason, it would be expected that farmers would rank udder diseases high. The finding that the small-scale farmers ranked milking environment as the biggest source of contamination is consistent with findings by Swai and Schoonman [6] who reported that milk spoilage will occur due to microorganisms from different sources including the animal itself and its surrounds. These microorganisms may be found in the environment arising from animal faeces, air, milking equipment, grass, soil, or the animal feed [6]. Although both large-scale and smallscale farmers ranked personnel as the least cause of spoilage, other findings indicate that that personnel cleanliness during milking and handling affects milk quality. The reason why 
both large-scale and small-scale farmers ranked personnel hygiene as the least source of milk contamination could be that the farmers in our study were reasonably confident with their personnel's hygiene and milking practises on farm but did not necessarily have the same level of confidence with other players in the milk supply chain like the transporters or processors. Thus, they would attribute deterioration of milk quality to handling by others in the supply chain. Contamination was therefore perceived to occur during storage or transportation. The major cause of poor milk quality for MCCs is expected to come from the use of unhygienic storage containers and during transportation [1]. Overall, the farmers' perception in this study indicates that there are many sources and causes of milk contamination.

The finding that the small-scale farmers were three times more concerned about milk quality could be attributed to the existence of penalty and premiums-based milk payment systems in developing countries. Milk quality would be a major concern as it affects profitability and the small-scale farmers are affected by milk pooling at the MCCs. In such cases farmers with good quality milk are affected by those with poor quality milk. For this reason, it was expected that the small-scale farmer would be more concerned about the milk quality in the absence of individualised milk quality testing as done in commercial farms. The adulteration of milk by one small-scale farmer can easily affect others in the consortium.

The finding that large-scale farmers considered milk safety to be important shows that the large-scale dairy farmers are not just interested in pushing milk volumes but also in the safety of the milk they produce for human consumption. The small-scale farmer may, on the other hand, prioritize the quantity of milk produced to safety. The high odds ratio estimate for the effect of education level on perceptions of milk safety can be attributed to differences in understanding of the importance and determinants of milk quality. Dairy producers who attain some level of formal education are more likely to have a better understanding on the importance and determinants of milk quality compared to the less educated. Education increases farmer's ability to obtain, analyse, and interpret milk quality issues. The lack of differences in the likelihood that small-scale and large-scale farmers consider milk quality to be important shows that although small-scale farmers are less likely to consider milk quality important, they are particular about its safety. Raw milk has been implicated for causing foodborne diseases and as a source of zoonotic bacteria such as Campylobacter, Escherichia coli, and Listeria $[8,18,19]$.

\section{Conclusions}

Farmers' perceptions of milk quality differed with milk production system, though differently ranked factors, such as production system, hygiene, breed, and age of farmers, affected perceptions on milk quality. Small-scale dairy farmers perceived that contamination during milking was mainly due to milking environment, whilst commercial farmers said it was mainly due to udder diseases. Small-scale farmers were less concerned about milk safety.

\section{Additional Points}

Practical Implications. One of the biggest concerns in the dairy industry is the quality and safety of milk. Although contamination of milk can occur at various stages in the value chain, most of the contamination is usually associated with the farm. Understanding farmer perceptions on factors affecting the quality and safety of milk will not only form the basis of intervention programmes for clean milk production but also assist farmers in putting in place mechanisms that ensure safe and profitable milk production.

\section{Conflicts of Interest}

The authors declare that there are no conflicts of interest regarding the publication of this article.

\section{Acknowledgments}

The authors are grateful to all the people who contributed and gave their time to this research. They would also like to acknowledge and thank the Dairy Services Zimbabwe directorate for their support in the collection of data.

\section{References}

[1] F. Moffat, S. Khanal, A. Bennett, T. Thapa, and S. George, "Technical and investment guidelines for milk cooling centres Technical and guidelines for milk cooling centres," FAO, 2016, http://www.fao.org/3/a-i5791e.pdf.

[2] C. D. Hahlani and J. Garwi, "Operational challenges to smallholder dairy farming: the case of mayfield dairy settlement scheme in chipinge district of Zimbabwe," IOSR Journal of Humanities and Social Science, vol. 19, no. 1, pp. 87-94, 2014.

[3] O. A. Ndambi, T. Hemme, and U. Latacz-Lohmann, "Dairying in Africa - Status and recent developments, Livestock research for rural development," Livestock Research for Rural Development, 2007.

[4] SNV, Zimbabwes Dairy Subsector Study, Stichting Nederlandse Vriwilligers, 2012, http://www.snv.org/public/cms/sites/default/ files/explore/download/rarp_2016-dairy-subsector-study.pdf.

[5] J. C. F. Pantoja, D. Reinemann, and P. L. Ruegg, "Associations among milk quality indicators in raw bulk milk," Journal of Dairy Science, vol. 92, no. 10, pp. 4978-4987, 2009.

[6] E. S. Swai and L. Schoonman, "Microbial quality and associated health risks of raw milk marketed in the Tanga region of Tanzania," Asian Pacific Journal of Tropical Biomedicine, vol. 1, no. 3, pp. 217-222, 2011.

[7] I. Verdier-Metz, V. Michel, C. Delbès, and M.-C. Montel, "Do milking practices influence the bacterial diversity of raw milk?" Food Microbiology, vol. 26, no. 3, pp. 305-310, 2009.

[8] S. Nada, D. Ilija, T. Igor, M. Jelena, and G. Ruzica, "Implication of food safety measures on microbiological quality of raw and pasteurized milk," Food Control, vol. 25, no. 2, pp. 728-731, 2012.

[9] J. Aertsens, W. Verbeke, K. Mondelaers, and G. van Huylenbroeck, "Personal determinants of organic food consumption: A review," British Food Journal, vol. 111, no. 10, pp. 1140-1167, 2009.

[10] K. G. Grunert, "Sustainability in the food sector: a consumer behaviour perspective," Int. J. Food System Dynamics, vol. 2, no. 3, pp. 207-218, 2011, http://dx.doi.org/10.18461/ijfsd.v2i3.232.218 ., doi. 
[11] R. Schleenbecker and U. Hamm, "Consumers' perception of organic product characteristics. A review," Appetite, vol. 71, pp. 420-429, 2013.

[12] SAS, Statistical Analytical Systems Guide for Personal Computers, North Carolina: Cary, 2008.

[13] A. Salami, A. B. Kamara, and Z. Brixiova, "Smallholder Agriculture in East Africa: Trends, Constraints and Opportunities," Working Paper No. 105 African Development Bank, 2010.

[14] K. Huijps, T. J. G. M. Lam, and H. Hogeveen, "Costs of mastitis: facts and perception," Journal of Dairy Research, vol. 75, no. 1, pp. 113-120, 2008.

[15] D. B. Nóbrega and H. Langoni, "Breed and season influence on milk quality parameters and in mastitis occurrence," Pesquisa Veterinária Brasileira, vol. 31, no. 12, pp. 1045-1052, 2011.

[16] K. A. Ellis, G. T. Innocent, M. Mihm et al., "Dairy cow cleanliness and milk quality on organic and conventional farms in the UK," Journal of Dairy Research, vol. 74, no. 3, pp. 302-310, 2007.

[17] L. Hassan, H. O. Mohammed, and P. L. McDonough, "Farmmanagement and milking practices associated with the presence of Listeria monocytogenes in New York state dairy herds," Preventive Veterinary Medicine, vol. 51, no. 1-2, pp. 63-73, 2001.

[18] I. Young, A. Rajić, S. Hendrick et al., "Attitudes towards the Canadian quality milk program and use of good production practices among Canadian dairy producers," Preventive Veterinary Medicine, vol. 94, no. 1-2, pp. 43-53, 2010.

[19] A. Ricci, K. Capello, V. Cibin et al., "Raw milk-associated foodborne infections: A scoring system for the risk-based categorisation of raw dairy farms," Research in Veterinary Science, vol. 95, no. 1, pp. 69-75, 2013. 


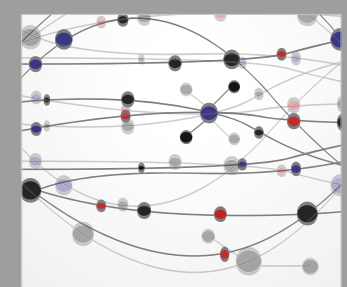

The Scientific World Journal
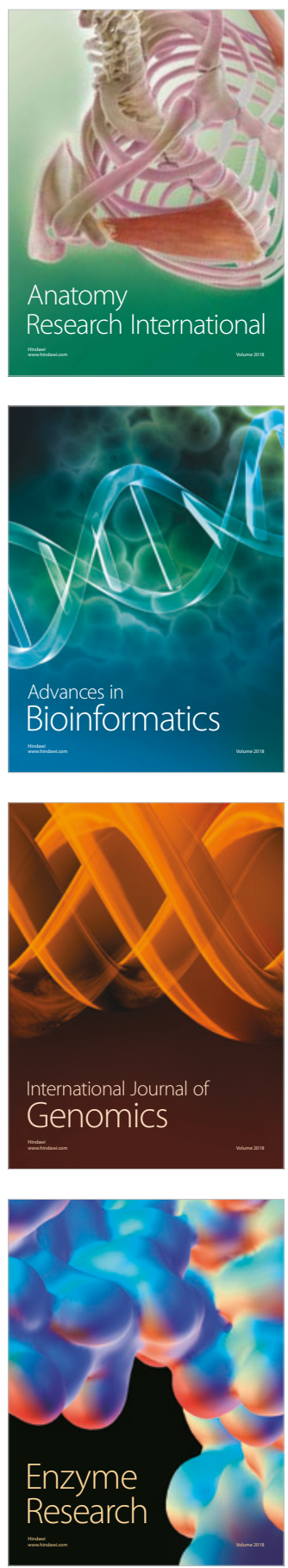
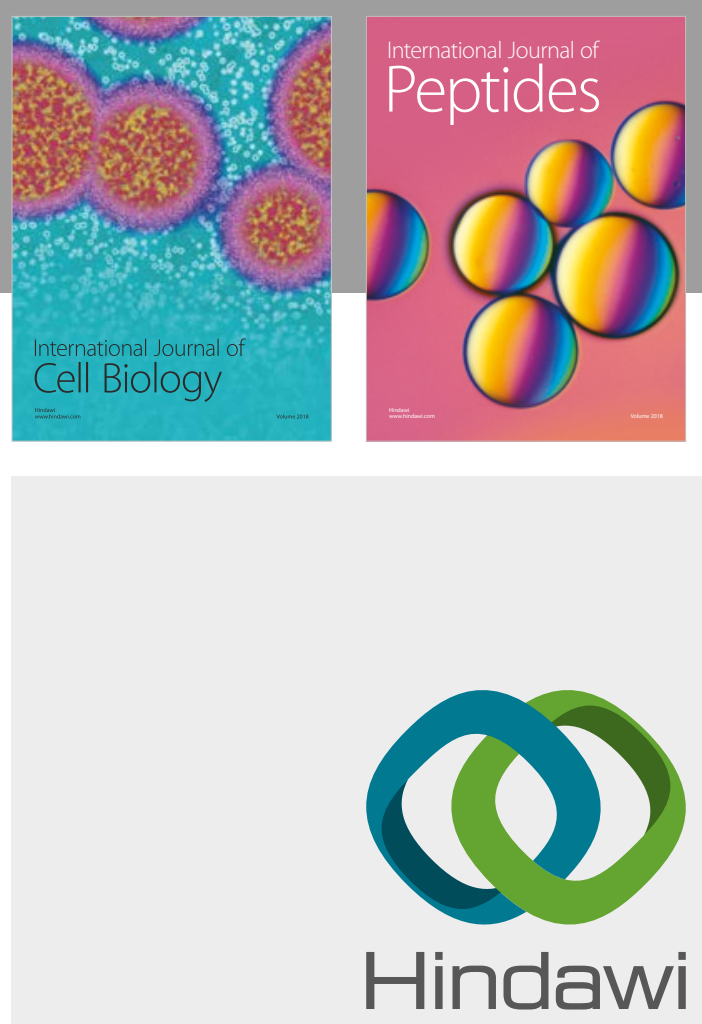

Submit your manuscripts at

www.hindawi.com
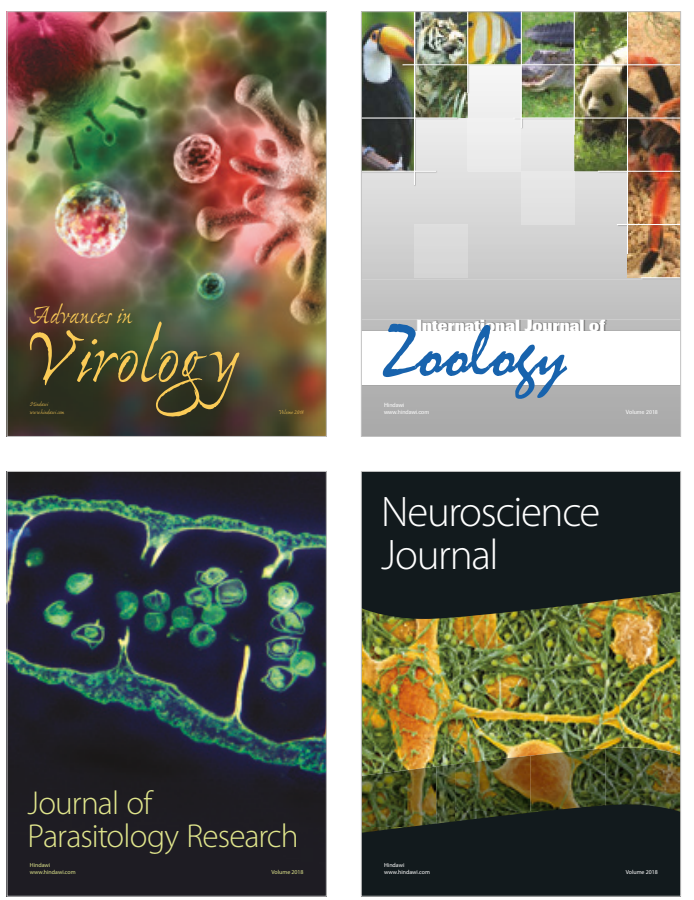
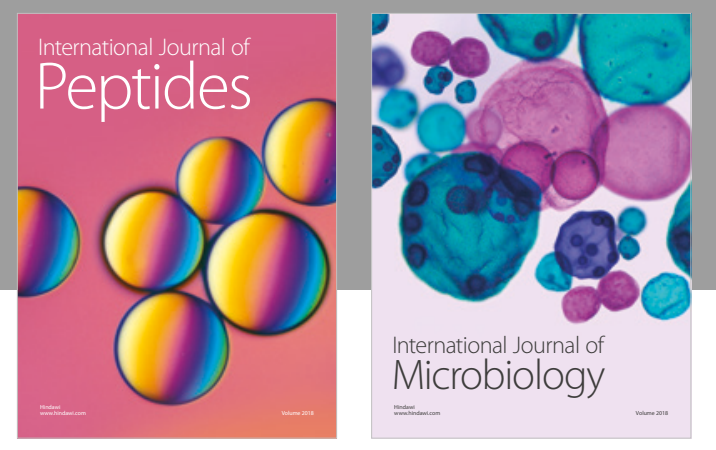

nternational Journal of Microbiology
Journal of
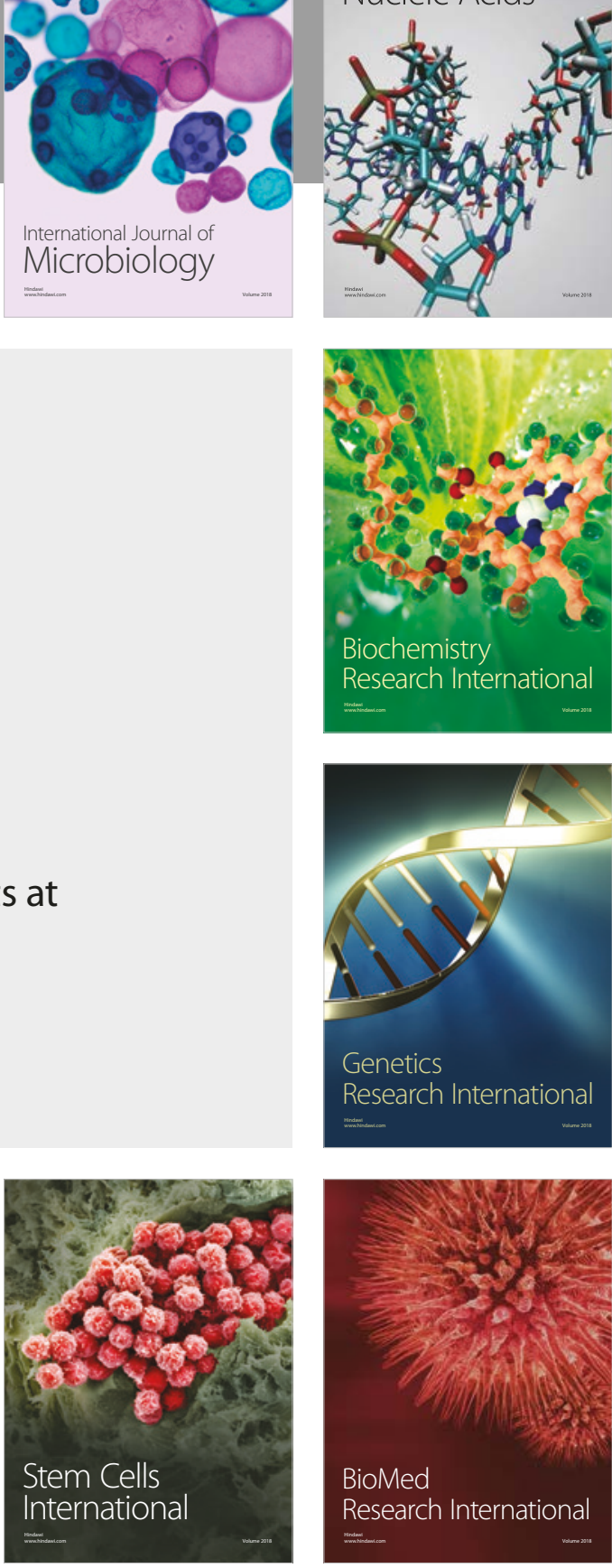
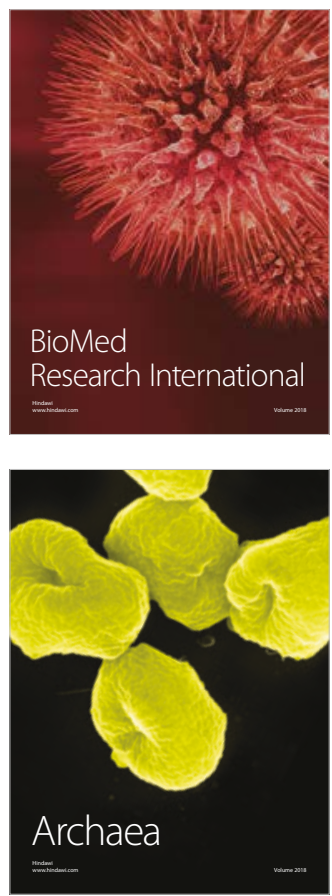